\title{
Downstream Breast Imaging Following Screening Mammography in Medicare Patients with Advanced Cancer: A Population-Based Study
}

\author{
Gelareh Sadigh, $M D^{7}$, Richard Duszak, Jr., MD ${ }^{7}$, Kevin C. Ward, PhD, MPH, CTR², \\ Renjian Jiang, $M P H^{2}$, Jeffrey M. Switchenko, $P h D^{3}$, Kimberly E. Applegate, MD, MS, FACR 4 , and \\ Ruth C. Carlos, MD, MS, FACR ${ }^{5}$
}

\begin{abstract}
'Department of Radiology and Imaging Sciences, Emory University School of Medicine, Atlanta, GA, USA; ${ }^{2}$ Department of Epidemiology, Emory University Rollins School of Public Health, Atlanta, GA, USA; ${ }^{3}$ Department of Biostatistics and Bioinformatics, Emory University Rollins School of Public Health, Atlanta, GA, USA; ${ }^{4}$ Department of Radiology, University of Kentucky, Lexington, KY, USA; ${ }^{5}$ Department of Radiology, University of Michigan, Ann Arbor, MI, USA.
\end{abstract}

BACKGROUND: Screening tests are generally not recommended in patients with advanced cancer and limited life expectancy. Nonetheless, screening mammography still occurs and may lead to follow-up testing.

OBJECTIVE: We assessed the frequency of downstream breast imaging following screening mammography in patients with advanced colorectal or lung cancer.

DESIGN: Population-based study.

PARTICIPANTS: The study included continuously enrolled female fee-for-service Medicare beneficiaries $\geq 65$ years of age with advanced colorectal (stage IV) or lung (stage IIIB-IV) cancer reported to a Surveillance, Epidemiology, and End Results (SEER) registry between 2000 and 2011.

MAIN MEASURES: We assessed the utilization of diagnostic mammography, breast ultrasound, and breast MRI following screening mammography. Logistic regression models were used to explore independent predictors of utilization of downstream tests while controlling for cancer type and patient sociodemographic and regional characteristics.

KEY RESULTS: Among 34,127 women with advanced cancer (23\% colorectal; $77 \%$ lung cancer; mean age at diagnosis 75 years), 9\% ( $n=3159)$ underwent a total of 5750 screening mammograms. Of these, $11 \%(n=639)$ resulted in at least one subsequent diagnostic breast imaging examination within 9 months. Diagnostic mammography was most common $(9 \% ; n=532)$, followed by ultrasound $(6 \% ; n=334)$ and MRI $(0.2 \% ; n=14)$. Diagnostic mammography rates were higher in whites than African Americans (OR, 1.6; $p<0.05$ ). Higher ultrasound utilization was associated with more favorable economic status (OR, 1.8; $p<0.05)$.

CONCLUSIONS: Among women with advanced colorectal and lung cancer, 9\% continued screening mammography, and $11 \%$ of these screening studies led to at least one additional downstream test, resulting in costs with little likelihood of meaningful benefit.

Received May 9, 2017

Revised September 12, 2017

Accepted October 11, 2017

Published online November 14, 2017
KEY WORDS: downstream tests; breast imaging; cancer survivorship; advanced cancer.

J Gen Intern Med 33(3):284-90

DOI: $10.1007 / \mathrm{s} 11606-017-4212-\mathrm{x}$

(c) Society of General Internal Medicine 2017

\section{INTRODUCTION}

Studies have shown that the absolute mortality benefit for women undergoing annual screening mammography over 10 years is approximately $10 \%{ }^{1,2}$ For this reason, breast cancer screening is generally not recommended in women with life expectancy of less than 5-7 years, ${ }^{3}$ such as those with advanced-stage cancer, severe morbidity, or advanced age.

Despite this, a small percentage of women with short life expectancy still undergo screening mammography, ${ }^{4-6}$ which may result in additional downstream breast imaging tests and procedures. Both are a potentially wasteful use of health care resources, ${ }^{7-9}$ and may cause additional psychological stress in the patient and/or their family members and caregivers ${ }^{10}$ from either false-positive results or identification of early breast cancers that would never lead to adverse outcomes (overdiagnosis).

We previously reported rates of screening mammography and its predictors in Medicare beneficiaries aged 67 years and older with advanced colorectal or lung cancer. ${ }^{4,11}$ The purpose of the current study was to examine and describe the utilization of downstream diagnostic breast imaging tests following screening mammography in female fee-for-service Medicare beneficiaries aged 65 years or older with advanced colorectal and lung cancer. We further explored predictors of downstream diagnostic breast imaging as well as the frequency that such patients underwent screening mammography more than once.

\section{METHODS}

Institutional review board approval and a waiver of informed consent were both obtained for this Health Insurance Portability and Accountability Act of 1996 (HIPAA)-compliant 
retrospective review of linked Surveillance, Epidemiology, and End Results (SEER) Program and Medicare claims data.

\section{Data Source}

SEER-Medicare, a cancer registry and claims-based database of medical care received by Medicare beneficiaries with cancer, was used for the current study. The database includes SEER program information from cancer registries covering approximately $28 \%$ of the U.S. population and fee-for-service claims for covered health care services (both Parts A and B benefits) for all SEER registry Medicare beneficiaries from the time of an individual's Medicare eligibility until death. ${ }^{12,13}$

\section{Study Population}

All female fee-for-service Medicare beneficiaries aged 65 years or older registered in SEER between 2000 and 2011 with a diagnosis of advanced colorectal or lung cancer (the most common non-breast malignancies in women ${ }^{14}$ ) were assessed for eligibility. Advanced cancer was defined as SEER-derived American Joint Committee on Cancer ${ }^{15}$ stage IV colorectal cancer or IIIB-IV lung cancer, which both generally have an overall 5-year survival of less than $20 \%$. ${ }^{5} 16$ We limited our study to advanced cancer patients, since screening mammography and its downstream diagnostic tests are considered an inappropriate use of health resources in this overall short-life-expectancy population. We excluded patients in whom colorectal or lung cancer was not their primary cancer, as well as those with an unknown month of cancer diagnosis, a diagnosis reported only from autopsy or death certificate, a date of death before date of diagnosis, or a death or breast cancer diagnosis within the first 3 months after the colorectal or lung cancer diagnosis. To ensure complete claims capture for predictive modeling, we only included patients continuously enrolled in Medicare Parts A Q1 and B from cancer diagnosis to a follow-up end-date, defined as a diagnosis of breast cancer, death, or the censoring date of December 31, 2013, whichever came first.

\section{Screening Mammography Utilization}

We further restricted our study to women who underwent at least one screening mammogram between 3 months after diagnosis and the follow-up end-date. Screening mammography services were identified as those reported with Current Procedural Terminology (CPT) codes 77057 or 76092 and Healthcare Common Procedure Coding System (HCPCS) codes G0202 or G0203. ${ }^{17}$ All duplicate claims were eliminated by matching patient identifier, procedure date, and CPT/ HCPCS code to prevent over-counting of services. Since screening mammograms are sometimes part of an initial diagnostic work-up, we did not include screening mammography services within the first 3 months of the lung or colorectal cancer diagnosis.

\section{Downstream Diagnostic Breast Imaging Utilization}

Diagnostic mammography (CPT 77055-77056, 7609076091; HCPCS G0204-G0207), breast ultrasound (CPT 76645) and breast MRI (CPT 77058-77059, 76093-76094) services performed within 9 months following the index screening mammography were identified and reported as the percentage of screening mammography services resulting in downstream diagnostic imaging tests. Based on prior work, the 9-month interval was chosen to help better distinguish between screening and diagnostic mammograms. ${ }^{18}$

\section{Study Outcomes}

The primary outcome was the utilization of downstream diagnostic imaging following screening mammography in Medicare beneficiaries with advanced colorectal and lung cancer.

The secondary outcome was exploring independent predictors of utilization of each downstream test following screening events while simultaneously controlling for all other covariates (i.e. cancer type, patient sociodemographic and regional characteristics).

The tertiary outcome was assessing independent predictors of women with advanced colorectal and lung cancer undergoing multiple screening mammography tests.

\section{Statistical Analysis}

Utilization of downstream diagnostic breast imaging tests following screening mammography was reported as a number and corresponding percentage. Multivariable logistic regression models were used to explore independent predictors of utilization of diagnostic mammography and breast ultrasound following screening events, as well as predictors of undergoing than one downstream diagnostic test in patients with at least one downstream test following a single mammography event. These analyses were conducted at the screening event level. Covariates of interest included cancer type (lung, colon), age at diagnosis $(65-69,70-74,75-79,>80$ years), marital status (married, not married), race/ethnicity (white, African American, other), a poverty index based on the census tract of the patient's residential address at the time of diagnosis (i.e. proportion of the census tract living below the federal poverty level: $0-<5 \%, 5-<10 \%, 10-<20 \%, 20-100 \%$ ), and geographic region (Northeast, Southeast, Midwest, West). Since one patient can have more than one screening event, within-patient correlation was accounted for using a generalized estimating equation assuming an exchangeable correlation structure. ${ }^{19}$ Predictors of MRI utilization as a downstream diagnostic test could not be assessed due to the small number patients who received MRI. We further assessed the independent predictors of undergoing more than one screening mammography in patients with at least one screening mammography using multivariable logistic regression models. Utilization of diagnostic mammography and breast ultrasound following 
the first screening mammography in patients with at least one screening mammography was assessed using the chi-square test. These analyses were conducted at the patient level. Multicollinearity was checked using variance inflation factors.

Statistical analyses were conducted in December 2016 using SAS version 9.2 software (SAS Institute Inc., Cary, NC). All significance tests were two-sided and used a 5\% level of significance.

\section{RESULTS}

\section{Study Population Characteristics}

Overall, 34,127 women with advanced colorectal or lung cancer met the inclusion criteria (Fig. 1). Baseline characteristics of cancer cases are shown in Table 1. Twenty-three percent of patients had colorectal and $77 \%$ had lung cancer. The mean age at diagnosis was 75 years $(\mathrm{SD}=7$, range 65 108); $84 \%$ of patients were white, and $37 \%$ were married at the time of their diagnosis.

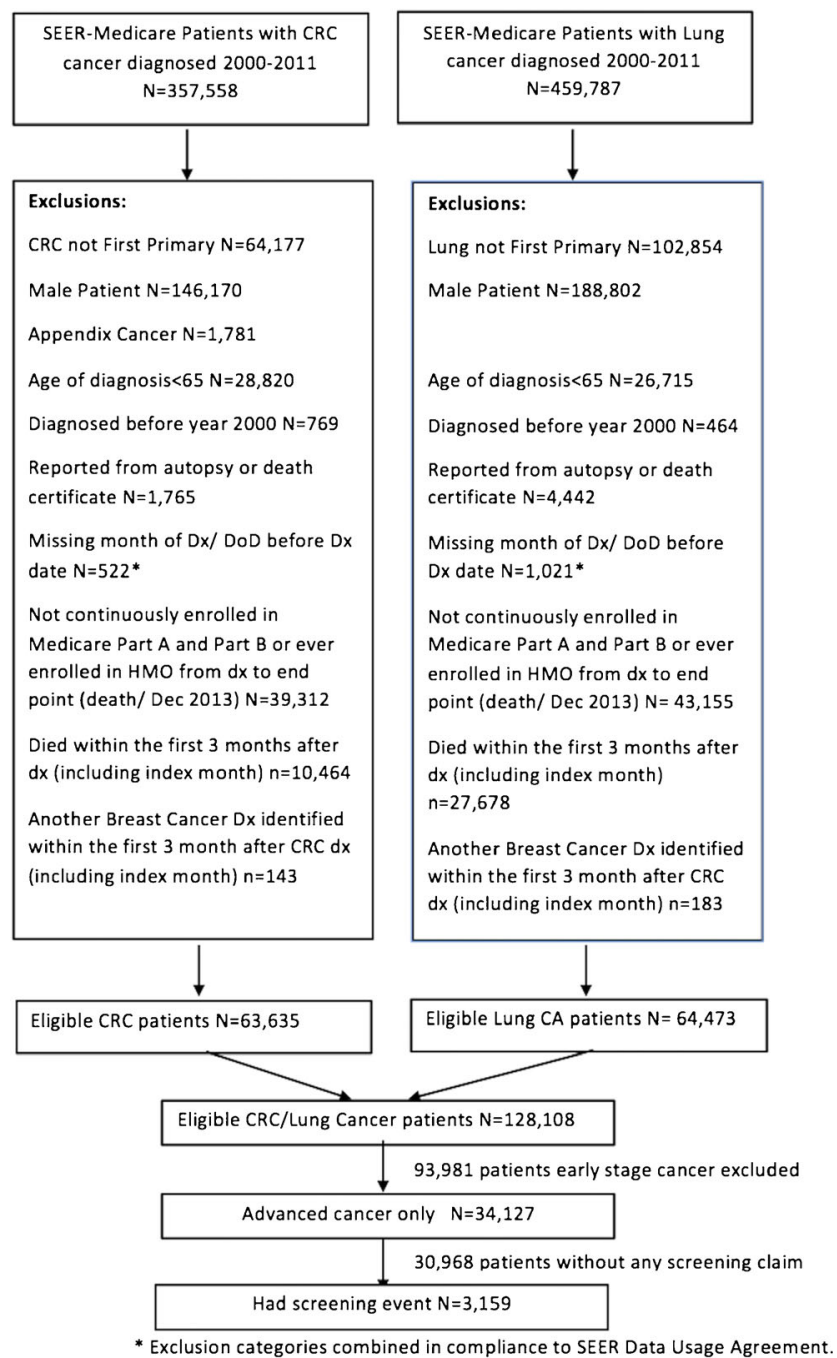

Figure 1 Study flowchart for primary outcome analysis. CRC, colorectal cancer; DoD, date of death; Dx, diagnosis.
Table 1 Baseline Characteristics of 34,127 Advanced Colorectal and Lung Cancer Patients

\begin{tabular}{ll}
\hline \hline Characteristics & $N=\mathbf{3 4 , 1 2 7}$ \\
\hline Cancer, no. (\%) & \\
Colorectal & $7843(23 \%)$ \\
Lung & $26,284(77 \%)$ \\
Age at diagnosis, years (SD) & $75(7)$ \\
Age at diagnosis, no. (\%) & \\
65-69 & $8245(24 \%)$ \\
$70-74$ & $8478(25 \%)$ \\
$75-79$ & $7820(23 \%)$ \\
>80 & $9584(28 \%)$ \\
Marital status, no. (\%) & \\
Married & $12,291(37)$ \\
Not married & $20,653(63)$ \\
Race, no. (\%) & \\
White & $28,795(84)$ \\
Black & $3313(10)$ \\
Other & $1964(6)$ \\
Poverty index, no. (\%) & \\
$0-<5 \%$ & $8521(25)$ \\
$5-<10 \%$ & $9314(27)$ \\
10-<20\% & $9599(28)$ \\
20-100\% & $6630(20)$ \\
SEER registry, no. (\%) & \\
Midwest & $7831(23)$ \\
Southeast & $11,576(34)$ \\
West & $7271(21)$ \\
Northeast & $7449(22)$ \\
\hline
\end{tabular}

Among women with newly diagnosed advanced colorectal or lung cancer, $9 \%(n=3159)$ underwent at least one screening mammogram. The total number of screening mammograms during the follow-up period was 5750, ranging from 1 to 12 per patient, with $38 \%$ ( $n=1188$ ) of women undergoing more than one screening mammogram.

\section{Downstream Diagnostic Breast Imaging Test Utilization}

Of 5750 screening mammograms performed in advanced cancer patients, $11 \%(n=639)$ were followed by at least one downstream diagnostic breast imaging exam within 9 months of the index screening mammogram. These downstream diagnostic tests were performed in 356 women (11\% of women who received a screening mammogram). Diagnostic mammography was the most common downstream diagnostic test $(9 \% ; n=532)$, followed by ultrasound $(6 \% ; n=334)$ and MRI $(0.2 \% ; n=14)$.

\section{Independent Predictors of Downstream Test Utilization}

Independent predictors of diagnostic mammography and breast ultrasound following 5750 screening mammograms, analyzed at the screening event level, are shown in Table 2. Diagnostic mammography rates were higher in whites than African Americans (OR, 1.6; 95\% CI, 1.1-2.3; $p=0.02)$ and lower in the Midwest (OR, 0.7; 95\% CI, 0.5-0.9; $p=0.008$ ) and West (OR, 0.6; 95\% CI, 0.5-0.9; $p=0.004$ ) than the Northeast (Table 2). Higher ultrasound rates were associated with more favorable economic status (OR, 1.8; 95\% CI, 1.22.7; $p=0.008$ for poverty index of less than $5 \%$ compared to index of $20-100 \%$ ). Table 3 illustrates utilization rates for 
Table 2 Independent Predictors of Downstream Diagnostic Breast Imaging Tests Following 5750 Screening Mammograms in Advanced Colorectal or Lung Cancer Patients*

\begin{tabular}{|c|c|c|}
\hline & $\begin{array}{l}\text { Diagnostic mammography } \\
\text { OR }(95 \% \text { CI })\end{array}$ & $\begin{array}{l}\text { Breast ultrasound } \\
\text { OR }(95 \% \text { CI })\end{array}$ \\
\hline \multicolumn{3}{|l|}{ Cancer type } \\
\hline $\begin{array}{l}\text { Colorectal vs. } \\
\text { lung }\end{array}$ & $\begin{array}{l}1.2(1-1.4) \\
(p=0.09)\end{array}$ & $\begin{array}{l}1(0.7-1.3) \\
(p=0.89)\end{array}$ \\
\hline \multicolumn{3}{|c|}{ Age, years (reference: >80) } \\
\hline $65-69$ & $\begin{array}{l}1.1(0.8-1.5) \\
(p=0.71)\end{array}$ & $\begin{array}{l}0.9(0.6-1.3) \\
(p=0.55)\end{array}$ \\
\hline $70-74$ & $\begin{array}{l}1.1(0.8-1.5) \\
(p=0.40)\end{array}$ & $\begin{array}{l}1(0.7-1.5) \\
(p=0.95)\end{array}$ \\
\hline $75-79$ & $\begin{array}{l}0.9(0.6-1.2) \\
(p=0.45)\end{array}$ & $\begin{array}{l}0.7(0.5-1.2) \\
(p=0.20)\end{array}$ \\
\hline \multicolumn{3}{|c|}{ Marital status (reference: not married) } \\
\hline Married & $\begin{array}{l}1(0.8-1.2) \\
(p=0.87)\end{array}$ & $\begin{array}{l}1(0.8-1.3) \\
(p=0.88)\end{array}$ \\
\hline \multicolumn{3}{|c|}{ Race (reference: African American) } \\
\hline White & $\begin{array}{l}1.6(1.1-2.3) \\
(p=0.02)\end{array}$ & $\begin{array}{l}1.3(0.8-2.1) \\
(p=0.22)\end{array}$ \\
\hline Other & $\begin{array}{l}1.2(0.7-2.2) \\
(p=0.53)\end{array}$ & $\begin{array}{l}0.9(0.4-1.9) \\
(p=0.74)\end{array}$ \\
\hline \multicolumn{3}{|c|}{ Poverty index (reference: $20-100 \%$ ) } \\
\hline $0-<5 \%$ & $\begin{array}{l}1.3(0.9-1.8) \\
(p=0.12)\end{array}$ & $\begin{array}{l}1.8(1.2-2.7) \\
(p=0.008)\end{array}$ \\
\hline $5-<10 \%$ & $\begin{array}{l}0.9(0.7-1.3) \\
(p=0.65)\end{array}$ & $\begin{array}{l}1.4(0.9-2.1) \\
(p=0.14)\end{array}$ \\
\hline $10-<20 \%$ & $\begin{array}{l}1.1(0.8-1.6) \\
(p=0.34)\end{array}$ & $\begin{array}{l}1.5(1-2.3) \\
(p=0.06)\end{array}$ \\
\hline \multicolumn{3}{|c|}{ SEER Registry (reference: Northeast) } \\
\hline Midwest & $\begin{array}{l}0.7(0.5-0.9) \\
(p=0.008)\end{array}$ & $\begin{array}{l}0.9(0.6-1.3) \\
(p=0.48)\end{array}$ \\
\hline Southeast & $\begin{array}{l}0.8(0.6-1) \\
(p=0.08)\end{array}$ & $\begin{array}{l}1.2(0.9-1.7) \\
(p=0.28)\end{array}$ \\
\hline West & $\begin{array}{l}0.6(0.5-0.9) \\
(p=0.004)\end{array}$ & $\begin{array}{l}1.1(0.7-1.6) \\
(p=0.36)\end{array}$ \\
\hline
\end{tabular}

* Sample size for breast MRI was too small for evaluation. Analyses were performed at the level of screening event

Boldface indicates statistical significance $(p<0.05)$

diagnostic mammography and breast ultrasound following first screening mammography in 3159 patients with at least one screening mammography, stratified by baseline characteristics.

\section{Independent Predictors of Multiple Screening Mammography and Downstream Tests}

Having more than one screening mammogram in advanced cancer patients was more frequently associated with colorectal than lung cancer (OR, $1.3 ; 95 \% \mathrm{CI}, 1.1-1.5 ; p=0.002)$, and with younger age (OR, 1.5; 95\% CI 1.2-2; $p<0.001$ for age $<70$; OR 1.5; 95\% CI, 1.2-1.9; $p=0.002$ for age 70-74).

In advanced cancer patients who underwent more than one downstream diagnostic imaging test within 9 months of a single screening mammogram, patients with colorectal cancer were less likely than lung cancer patients to have more than one downstream diagnostic breast imaging test (Table 4).

\section{DISCUSSION}

Using linked SEER registry and Medicare claims data, we found that $9 \%$ of Medicare fee-for-service beneficiaries with advanced colorectal or lung cancer and short life expectancy underwent screening mammography post-diagnosis, and $11 \%$ of those screening mammograms were followed by at least one downstream diagnostic breast imaging test.

The American College of Radiology and the U.S. Department of Health \& Human Services Agency for Healthcare Policy and Research both recommend overall diagnostic imaging recall rates of less than $10 \%$ for women undergoing screening mammography. ${ }^{20,21}$ The $11 \%$ recall rate in our study shows that women with advanced cancer are called back for positive screening mammograms at a frequency similar to that in the general population. In advanced cancer patients, however, the overall rationale for screening mammography and recall is likely inappropriate, as these women usually do not live long enough to benefit from improved mortality associated with this screening. ${ }^{3,22}$ Therefore, in this population, there is probably a net harm caused by performing imaging tests which is manifested in false-positive diagnoses, overdiagnosis of early cancers that do not result in adverse outcomes, ${ }^{23}$ overtreatment (including unnecessary diagnostic image-guided breast procedures as a result of a positive downstream diagnostic test-something we did not study), and additional stress, regardless of whether a breast cancer is diagnosed, in patients and family members who are already distressed from the primary cancer diagnosis. ${ }^{10}$

The mean age at diagnosis for patients included in our study was 75 years (51\% were older than 75$)$. The U.S. Preventive Services Task Force (USPSTF) offers no definite recommendations for screening mammography in this population, since data is inconclusive about the survival benefits of screening in older patients with shorter life expectancies. ${ }^{24}$ In patients with advanced cancer, however, screening is likely of far less value. Our data show the rate of downstream diagnostic tests was similar in women both younger and older than 75 . In prior work, we showed that screening mammography utilization rates in patients with advanced colorectal and lung cancer are significantly lower than cancer-free matched controls $(8 \%$ vs. $18 \%) .{ }^{4}$ In addition, as advanced cancer patients age, utilization rates of screening mammography decline. ${ }^{11}$ Indeed, our findings confirm that the rate of multiple screening mammography decreases as patients age. However, regardless of age, once a patient has received a screening mammography, there is no significant difference in the likelihood of receiving downstream diagnostic test.

Finally, there are financial burdens associated with unnecessary imaging near the end of life. More than $25 \%$ of Medicare dollars are spent in the last year of life, ${ }^{25}$ and cancer consumes a great proportion of overall Medicare expenditures. ${ }^{26}$ Researchers have found that the total cost per person over the last year of life in patients with poor prognostic cancers was $\$ 71,517$ for non-hospice and $\$ 62,819$ for hospice populations. ${ }^{27}$ Among Medicare cancer patients, imaging costs until recently have risen at a rate outpacing total cost of care, ${ }^{28}$ and are likely to further increase as the prevalence of cancer is expected to continue to increase given our aging population. $^{29,30}$ 
Table 3 Utilization of Downstream Diagnostic Imaging Following First Screening Mammography in 3159 Advanced Cancer Patients with at Least One Screening Mammogram, Stratified by Baseline Characteristics*

\begin{tabular}{|c|c|c|c|c|c|c|}
\hline & \multicolumn{3}{|c|}{ Diagnostic mammography } & \multicolumn{3}{|l|}{ Ultrasound } \\
\hline & $\begin{array}{l}\text { No } \\
n=2863\end{array}$ & $\begin{array}{l}\text { Yes } \\
n=296\end{array}$ & $p$-value ${ }^{\dagger}$ & No $n=2975$ & Yes $n=184$ & $p$-value ${ }^{\dagger}$ \\
\hline \multicolumn{7}{|l|}{ Cancer, no. (\%) } \\
\hline Colorectal & $783(91)$ & $81(9)$ & 0.99 & $818(95)$ & $46(5)$ & 0.46 \\
\hline Lung & $2080(91)$ & $215(9)$ & & $2157(94)$ & $138(6)$ & \\
\hline \multicolumn{7}{|c|}{ Age at diagnosis (years), no. $(\%)$} \\
\hline $65-69$ & $996(91)$ & $98(9)$ & 0.45 & $1032(94)$ & $62(6)$ & 0.30 \\
\hline $70-74$ & $822(89)$ & $98(11)$ & & $860(93)$ & $60(7)$ & \\
\hline $75-79$ & $642(91)$ & $60(9)$ & & $670(95)$ & $32(5)$ & \\
\hline$>80$ & $403(91)$ & $40(9)$ & & $413(93)$ & $30(7)$ & \\
\hline \multicolumn{7}{|c|}{ Marital status, no. (\%) } \\
\hline Married & $1437(91)$ & $138(9)$ & 0.23 & $1483(94)$ & $92(6)$ & 0.89 \\
\hline Not married & $1345(90)$ & $150(10)$ & & $1406(94)$ & 89 (6) & \\
\hline \multicolumn{7}{|l|}{ Race, no. (\%) } \\
\hline White & $2414(90)$ & $>269(>10)$ & 0.004 & $2519(94)$ & $>162(>6)$ & 0.13 \\
\hline Black & $278(95)$ & $16(5)$ & & $283(96)$ & $11(4)$ & \\
\hline Other ${ }^{+}$ & $171(94)$ & $<11(<6)$ & & $173(94)$ & $<11(<6)$ & \\
\hline \multicolumn{7}{|c|}{ Poverty index, no. (\%) } \\
\hline $0-<5 \%$ & $734(88)$ & $100(12)$ & 0.03 & $774(93)$ & $60(7)$ & 0.08 \\
\hline $5-<10 \%$ & $851(91)$ & $82(9)$ & & $878(94)$ & $55(6)$ & \\
\hline $10-<20 \%$ & $789(92)$ & $70(8)$ & & $810(94)$ & $49(6)$ & \\
\hline $20-100 \%$ & $484(92)$ & $44(8)$ & & $508(96)$ & $20(4)$ & \\
\hline \multicolumn{7}{|c|}{ SEER registry, no. (\%) } \\
\hline Midwest & $585(88)$ & $80(12)$ & 0.02 & $628(94)$ & $37(6)$ & 0.08 \\
\hline Southeast & $629(93)$ & $49(7)$ & & $651(96)$ & $27(4)$ & \\
\hline West & $1038(90)$ & $111(10)$ & & $1076(94)$ & $73(6)$ & \\
\hline Northeast & $611(92)$ & $56(8)$ & & $620(93)$ & $47(7)$ & \\
\hline
\end{tabular}

*Sample size for breast MRI was too small for evaluation. Analyses were performed at the patient level

The parametric p-value was calculated by chi-square test. Boldface indicates statistical significance $(p<0.05)$

$¥$ Cells $<11$ masked in compliance with SEER Data Use Agreement

Both screening mammography and recall in advanced cancer patients are examples of clinical waste due to the provision of low-value services. ${ }^{7}$ These events can be reduced by promoting greater use of clinical guidelines and provider decision support tools by primary care providers, oncologists and palliative care specialists alike; involving patients and their families or care givers in care decisions through an informed decision-making process; realigning financial incentives to promote delivery of high-quality, low-cost care; and improving transparency in quality and cost of imaging tests. ${ }^{9}$ Although we did not assess differential screening mammography order rates by physician specialty for patients with advanced cancer, it is important that all clinicians assess the benefits and risks associated with screening tests for each individual patient and avoid unnecessary tests during end-of-life care in advanced cancer patients.

Predictors of undergoing at least one screening mammogram were previously reported in these patients with advanced colorectal and lung cancer. ${ }^{11,16}$ In the current study, we found that younger age and colorectal cancer (compared to lung cancer) were associated with higher rates of undergoing more than one screening mammography in patients with advanced cancer. This is likely because the majority of breast cancer screening guideline recommendations are based on patient age (currently up to age 75 years), as well as a higher probability of survival in younger patients and in advanced colorectal cancer patients compared to those with lung cancer within the same amount of follow-up time. ${ }^{5}$ Similar to the population receiving screening mammography, being white was associated with higher rates of downstream diagnostic mammography, which is in keeping with the higher incidence of breast cancer among white women than African Americans. ${ }^{31}$ In addition, more favorable economic status was associated with higher rates of breast ultrasound.

Low socioeconomic status has been a consistent marker for underuse of screening mammography in the general population, likely due to higher uninsured rates and lack of a usual source of care. ${ }^{32}$ Disparities in screening mammography utilization among African-American women with Medicare feefor-service insurance has been reported previously. ${ }^{32}$ However, in the case of advanced cancer patients, where the use of any screening or diagnostic breast imaging test is likely unnecessary, the disparity in utilization of imaging tests in African-American women and those with less favorable economic status is associated with more appropriate use of resources.

Although prior studies have shown that women with colorectal cancer (regardless of cancer stage) ${ }^{16}$ and those with advanced colorectal cancer ${ }^{11}$ are more likely to undergo screening mammography, the results of our current study revealed that women with advanced colorectal cancer and at least one downstream test were less likely than lung cancer patients to receive multiple downstream diagnostic tests following a single mammography event. This might be due to the proximity of the lungs and breasts, resulting in suspicion that a positive screening mammogram might be the result of lung 
Table 4 Independent Predictors of Multiple Screening Mammography and Downstream Diagnostic Breast Imaging Tests in Advanced Colorectal or Lung Cancer Patients*

\begin{tabular}{|c|c|c|}
\hline & $\begin{array}{l}\text { Multiple screening } \\
\text { mammography tests } \\
\text { OR }(95 \% \text { CI) }\end{array}$ & $\begin{array}{l}\text { Multiple } \\
\text { downstream tests } \\
\text { OR }(95 \% \mathrm{CI})\end{array}$ \\
\hline \multicolumn{3}{|l|}{ Cancer type } \\
\hline $\begin{array}{l}\text { Colorectal } \\
\text { vs. lung }\end{array}$ & $\begin{array}{l}1.3(1.1-1.5) \\
(p=0.002)\end{array}$ & $\begin{array}{l}0.6(0.4-0.8) \\
(p=0.003)\end{array}$ \\
\hline \multicolumn{3}{|c|}{ Age, years (reference: $>80$ ) } \\
\hline 65-69 & $\begin{array}{l}1.5(1.2-2) \\
(p<0.001)\end{array}$ & $\begin{array}{l}0.7(0.4-1.2) \\
(p=0.19)\end{array}$ \\
\hline $70-74$ & $\begin{array}{l}1.5(1.2-1.9) \\
(p=0.002)\end{array}$ & $\begin{array}{l}0.7(0.4-1.3) \\
(p=0.24)\end{array}$ \\
\hline $75-79$ & $\begin{array}{l}1.3(1-1.6) \\
(p=0.09)\end{array}$ & $\begin{array}{l}0.7(0.4-1.3) \\
(p=0.27)\end{array}$ \\
\hline \multicolumn{3}{|c|}{ Marital status (reference: not married) } \\
\hline Married & $\begin{array}{l}1(0.9-1.2) \\
(p=0.62)\end{array}$ & $\begin{array}{l}1(0.7-1.4) \\
(p=0.88)\end{array}$ \\
\hline \multicolumn{3}{|c|}{ Race (reference: African American) } \\
\hline White & $\begin{array}{l}1.2(0.9-1.5) \\
(p=0.31)\end{array}$ & $\begin{array}{l}0.5(0.3-1.1) \\
(p=0.07)\end{array}$ \\
\hline Other & $\begin{array}{l}0.8(0.5-1.3) \\
(p=0.39)\end{array}$ & $\begin{array}{l}1.1(0.3-3.6) \\
(p=0.86)\end{array}$ \\
\hline \multicolumn{3}{|c|}{ Poverty index (reference: $20-100 \%$ ) } \\
\hline $0-<5 \%$ & $\begin{array}{l}1.2(0.9-1.5) \\
(p=0.14)\end{array}$ & $\begin{array}{l}1.3(0.7-2.4) \\
(p=0.31)\end{array}$ \\
\hline $5-<10 \%$ & $\begin{array}{l}1(0.8-1.3) \\
(p=0.88)\end{array}$ & $\begin{array}{l}1.9(1.1-3.5) \\
(p=0.03)\end{array}$ \\
\hline $10-<20 \%$ & $\begin{array}{l}1(0.8-1.2) \\
(p=0.78)\end{array}$ & $\begin{array}{l}1.6(0.9-2.9) \\
(p=0.12)\end{array}$ \\
\hline \multicolumn{3}{|c|}{ SEER registry (reference: Northeast) } \\
\hline Midwest & $\begin{array}{l}1.1(0.8-1.3) \\
(p=0.59)\end{array}$ & $\begin{array}{l}0.9(0.6-1.6) \\
(p=0.83)\end{array}$ \\
\hline Southeast & $\begin{array}{l}1(0.8-1.2) \\
(p=0.99)\end{array}$ & $\begin{array}{l}0.7(0.5-1.1) \\
(p=0.14)\end{array}$ \\
\hline West & $\begin{array}{l}1.1(0.9-1.4) \\
(p=0.29)\end{array}$ & $\begin{array}{l}1.3(0.5-1.5) \\
(p=0.61)\end{array}$ \\
\hline
\end{tabular}

*Analyses were performed at the patient level for multiple screening mammography and at the screening event level for multiple downstream tests

Boldface indicates statistical significance $(p<0.05)$

cancer metastasis to the breasts, needing further work-up, although breasts are not a common location of lung cancer spread. ${ }^{33}$ Prior studies have shown that advanced cancer patients in certain geographic regions (e.g. the Midwest, Southeast and West) have a higher likelihood of undergoing screening mammography than those in the Northeast. ${ }^{11}$ Our study, however, shows a lower likelihood of diagnostic mammography in those regions, but the reason for this discrepancy is not clear.

A study by Sima et al. in advanced colorectal and lung cancer patients from the SEER-Medicare database (1998-2005) demonstrated median overall survival (from the time of cancer diagnosis until death) of 8 months for lung cancer and 11 months for colorectal cancer patients. ${ }^{5}$ Our prior study of screening mammography utilization in cancer patients showed median followup times (from cancer diagnosis) of 8 months for lung and 11 months for colorectal cancer, ${ }^{4}$ confirming short survival in this population. In the Sima et al. study, half of the patients who received screening mammography did so within 10 months of the cancer diagnosis, and most patients screened had testing within 36 months of diagnosis. We would expect a similar pattern of results for our patient population. In addition, given that $11 \%$ of patients with screening mammography received downstream imaging within 9 months, and considering the short survival of these patients, we would expect a majority of patients with downstream testing to have received it within the first 2 years of cancer diagnosis.

This study has several limitations. First, screening mammography events were determined using CPT and HCPCS billing codes. One study has suggested that screening mammography rates are underestimated when relying solely on screening mammography codes, given the potential for uncertainty in distinguishing these services from diagnostic mammograms. ${ }^{18}$ Furthermore, the determination of downstream diagnostic breast imaging tests using claims billing codes is challenging. In the current study, we considered any diagnostic test performed within 9 months after screening mammography as a downstream test, but recognize that some of these tests may have been performed independently of the screening mammogram (e.g., negative screening mammogram, but later development of a palpable mass). In addition, to ensure the accuracy of our predictive model, we included only patients who were continuously enrolled in Medicare both Parts A and $\mathrm{B}$, and therefore, the percentage of screening mammograms is likely underestimated. Finally, the independent predictors of breast MRI utilization could not be explored due to the small sample size of patients who received MRI.

\section{CONCLUSION}

In summary, our study results show that in Medicare-aged women with advanced colorectal and lung cancer, $9 \%$ still underwent screening mammography, and $11 \%$ of these screening mammograms were followed by at least one additional downstream diagnostic breast imaging examination, resulting in costs without the likelihood of meaningful benefit during the near-end-of-life period. Further, women with more favorable economic status and white women were more likely to receive downstream breast ultrasound and diagnostic mammography, respectively. Identifying areas of overutilization during the period near the end of life could help in targeting interventions to improve clinical practice and reduce the costs of cancer care.

Acknowledgements: Research reported in this publication was supported by the Radiological Society of North America Research and Education Foundation under award number RR1553. This research was also supported in part by the Biostatistics and Bioinformatics Shared Resource of the Winship Cancer Institute of Emory University and the National Institutes of Health/National Cancer Institute (NIH/NCI) under award number P3OCA138292. This study used the linked SEER-Medicare database. The authors acknowledge the efforts of the Applied Research Program, National Cancer Institute; the Office of Research, Development, and Information, CMS; Information Management Services, Inc.; and the Surveillance, Epidemiology, and End Results (SEER) program tumor registries in the creation of the SEER-Medicare database. Institutional review board approval and a waiver of informed consent were both obtained under IRB\# IRBO0081613. The interpretation and reporting of these data are the sole responsibility of the authors. The abstract of this manuscript was presented at the Association of University Radiologists (AUR) annual meeting in May 2017, and was awarded the scientific trainee prize. 
Corresponding Author: Gelareh Sadigh, MD; Department of Radiology and Imaging SciencesEmory University School of Medicine, 1364 Clifton Rd, Atlanta, GA 30322, USA (e-mail: gsadigh@emory.edu).

\section{Compliance with Ethical Standards:}

Conflict of Interest: The authors declare that they have no conflict of interest.

\section{REFERENCES}

1. Moss SM, Cuckle H, Evans A, et al. Effect of mammographic screening from age 40 years on breast cancer mortality at 10 years' follow-up: a randomised controlled trial. Lancet. 2006;368(9552):2053-60. https:// doi.org/10.1016/S0140-6736(06)69834-6

2. National Cancer Institute. Breast Cancer Screening (PDQ $\left.{ }^{\circledR}\right)$. Available at: https://www.cancer.gov/types/breast/hp/breast-screening-pdq. Accessed on Oct 6, 2017.

3. Lee CH, Dershaw DD, Kopans D, et al. Breast cancer screening with imaging: recommendations from the Society of Breast Imaging and the ACR on the use of mammography, breast MRI, breast ultrasound, and other technologies for the detection of clinically occult breast cancer. J Am College Radiol. 2010;7(1):18-27. https://doi.org/10.1016/j.jacr. 2009.09.022

4. Sadigh G, Carlos RC, Ward KC, et al. Breast Cancer Screening in Patients With Newly Diagnosed Lung and Colorectal Cancer: A Population-Based Study of Utilization. J Am College Radiol. 2017;14(7):900-10. https://doi.org/10.1016/j.jacr.2017.01.022

5. Sima CS, Panageas KS, Schrag D. Cancer screening among patients with advanced cancer. JAMA. 2010;304(14):1584-91. https://doi.org/ 10.1001/jama.2010.1449

6. Walter LC, Covinsky KE. Cancer screening in elderly patients: a framework for individualized decision making. JAMA. 2001;285(21):2750-6.

7. Bentley TG, Effros RM, Palar K, Keeler EB. Waste in the U.S. Health care system: a conceptual framework. Milbank Q. 2008;86(4):629-59. https://doi.org/10.1111/j.1468-0009.2008.00537.x

8. Schwartz AL, Landon BE, Elshaug AG, Chernew ME, McWilliams JM. Measuring low-value care in Medicare. JAMA Intern Med. 2014;174(7):1067-76. https://doi.org/10.1001/jamainternmed.2014. 1541

9. "Reducing Waste in Health Care," Health Affairs Health Policy Brief, December 13, 2012. DOI: 10.1377/hpb20121213.959735

10. Lerman C, Trock B, Rimer BK, Boyce A, Jepson C, Engstrom PF. Psychological and behavioral implications of abnormal mammograms. Ann Intern Med. 1991;114(8):657-61.

11. Sadigh G, Carlos RC, Ward K, et al. Predictors of Screening Mammography in Patients with Early vs. Advanced Stage Colorectal and Lung Cancer: A Population-Based Study. American College of Radiology annual meeting; Chicago, IL. May 2017. Available at: https://www.acr.org/ /media/ACR/Documents/PDF/Annual-Meeting/Abstracts/2017/ 17020_Sadigh.pdf?la=en. Accessed on Novemebr 10, 2017

12. National Cancer Institute. SEER-Medicare linked database. Available at: http://appliedresearch.cancer.gov/seermedicare/. Accessed on Oct 6, 2017.

13. Warren JL, Klabunde CN, Schrag D, Bach PB, Riley GF. Overview of the SEER-Medicare data: content, research applications, and generalizability to the United States elderly population. Med Care. 2002;40(8 Suppl):IV-318. https://doi.org/10.1097/01.MLR.0000020942.47004.03

14. Centers for Disease Control and Prevention. Cancer Prevention and Control. Available at: http://www.cdc.gov/cancer/dcpc/data/women. htm. Accessed on Oct 6, 2017.

15. AJCC Cancer Staging Manual. 7th ed. New York, NY: Springer; 2009.

16. Sadigh G, Carlos RC, Ward K, et al. Breast Cancer Screening in Patients with Newly Diagnosed Lung and Colorectal Cancer. J Am Coll Radiol. 2017 Jul;14(7):900-910. https://doi.org/10.1016/j.jacr.2017.01.022 .

17. CPT Standard Edition: Current Procedural Terminology. Chicago, IL: American Medical Association, 2013.

18. Fenton JJ, Zhu W, Balch S, Smith-Bindman R, Fishman P, Hubbard RA. Distinguishing screening from diagnostic mammograms using Medicare claims data. Med Care. 2014;52(7):e44-51. https://doi.org/ 10.1097/MLR.0b013e318269e0f5

19. Liang KY, Zeger SL. Longitudinal data analysis using generalized linear models. Biometrika. 1986;73(1):13-22.

20. Quality determinants of mammography: guideline overview. Agency for Health Care Policy and research. J Natl Med Assoc. 1995;87(2):91-2.

21. Feig SA, D'Orsi CJ, Hendrick RE, et al. American College of Radiology guidelines for breast cancer screening. Am J Roentgenol. 1998;171(1):2933. https://doi.org/10.2214/ajr.171.1.9648758

22. Kerlikowske K, Grady D, Rubin SM, Sandrock C, Ernster VL. Efficacy of screening mammography. A meta-analysis. JAMA. 1995;273(2):14954.

23. Jorgensen $\mathbf{K J}$, Gotzsche PC. Overdiagnosis in publicly organised mammography screening programmes: systematic review of incidence trends. BMJ. 2009;339:b2587. https://doi.org/10.1136/bmj.b2587

24. U.S. Preventive Services Task Force. Screening for breast cancer: U.S. Preventive Services Task Force recommendation statement. Ann Intern Med. 2009;151(10):716-26, W-236. https://doi.org/10.7326/00034819-151-10-200911170-00008

25. Riley GF, Lubitz JD. Long-term trends in Medicare payments in the last year of life. Health Serv Res. 2010;45(2):565-76. https://doi.org/10. $1111 /$ j.1475-6773.2010.01082.x

26. Meropol NJ, Schrag D, Smith TJ, et al. American Society of Clinical Oncology guidance statement: the cost of cancer care. J Clin Oncol. 2009;27(23):3868-74. https://doi.org/10.1200/JCO.2009.23.1183

27. Obermeyer Z, Makar M, Abujaber S, Dominici F, Block S, Cutler DM. Association between the Medicare hospice benefit and health care utilization and costs for patients with poor-prognosis cancer. JAMA. 2014;312(18):1888-96. https://doi.org/10.1001/jama.2014.14950

28. Dinan MA, Curtis LH, Hammill BG, et al. Changes in the use and costs of diagnostic imaging among Medicare beneficiaries with cancer, 19992006. JAMA. 2010;303(16):1625-31. https://doi.org/10.1001/jama. 2010.460

29. Yabroff KR, Lamont EB, Mariotto A, et al. Cost of care for elderly cancer patients in the United States. J Natl Cancer Inst. 2008;100(9):630-41. https://doi.org/10.1093/jnci/djn 103

30. Ries LAG, Harkins D, Krapcho M, et al. SEER Cancer Statistic Review, 1975-2003. Bethesda, MD: National Cancer Institute; 2006.

31. Centers for Disease Control and Prevension. Breast Cancer Rates by Race and Ethnicity. Available at: https://www.cdc.gov/cancer/breast/statistics/race.htm. Accessed on Oct 6, 2017.

32. Peek ME, Han JH. Disparities in screening mammography. Current status, interventions and implications. J Gen Intern Med. 2004; 19(2): 184-94.

33. National Cancer Institute. Metastatic cancer. Available at: https://www. cancer.gov/types/metastatic-cancer. Accessed on Oct 6, 2017. 